\title{
Circularly Polarized Low-Profile Antenna for Radiating Parallel to Ground Plane for RFID Reader Applications
}

\author{
Kittima Lertsakwimarn, ${ }^{1}$ Chuwong Phongcharoenpanich, ${ }^{1}$ and Takeshi Fukusako ${ }^{2}$ \\ ${ }^{1}$ Faculty of Engineering, King Mongkut's Institute of Technology Ladkrabang, Chalongkrung Road, Ladkrabang, \\ Bangkok 10520, Thailand \\ ${ }^{2}$ Graduate School of Science and Technology, Kumamoto University, 2-39-1 Kurokami, Chuo-ku, Kumamoto 860-8555, Japan \\ Correspondence should be addressed to Kittima Lertsakwimarn; wimand.mai@gmail.com
}

Received 4 September 2013; Revised 4 October 2013; Accepted 5 October 2013

Academic Editor: Z. N. Chen

Copyright (C) 2013 Kittima Lertsakwimarn et al. This is an open access article distributed under the Creative Commons Attribution License, which permits unrestricted use, distribution, and reproduction in any medium, provided the original work is properly cited.

\begin{abstract}
This paper presents a low-profile printed antenna with double U-shaped arms radiating circular polarization for the UHF RFID readers. The proposed antenna consists of double U-shaped strip structures and a capacitive feeding line to generate circular polarization. A part of the U-shaped arms is bent by $90^{\circ}$ to direct the main beam parallel to the ground plane. From the results, $-10 \mathrm{~dB}\left|\mathrm{~S}_{11}\right|$ and $3 \mathrm{~dB}$ axial ratio of the antenna cover a typical UHF RFID band from $920 \mathrm{MHz}$ to $925 \mathrm{MHz}$. The bidirectional beam is obtained with the maximum gain of $1.8 \mathrm{dBic}$ in the parallel direction to the ground plane at the $925 \mathrm{MHz}$. The overall size of the proposed antenna including ground plane is $107 \mathrm{~mm} \times 57 \mathrm{~mm} \times 12.8 \mathrm{~mm}\left(0.33 \lambda_{0} \times 0.17 \lambda_{0} \times 0.04 \lambda_{0}\right)$.
\end{abstract}

\section{Introduction}

Radio frequency identification (RFID) systems in the ultrahigh-frequency (UHF) band are getting a standard in widely used for many applications such as supply chain management, logistics, and tracking [1]. Different frequency ranges for the UHF RFID band have been allocated depending on countries and regions such as $865-868 \mathrm{MHz}$ in Europe, 902$928 \mathrm{MHz}$ in North and South Americas, $950-956 \mathrm{MHz}$ in Japan, and $920-925 \mathrm{MHz}$ in some Asian countries. Many linearly polarized reader antennas have been designed with small size and sufficient bandwidth and used for RFID systems; however, a problem of missing tag detection may take place due to a polarization mismatch. For avoiding this problem, the use of antennas radiating circular polarization (CP) can be a good option $[2,3]$.

On the other hand, portable RFID readers in addition to fixed type of readers have been actively used in recent years. Considering this situation, antennas for handheld RFID readers have been required to have a low-profile and a small size structure with light weight [4-9]. In fact, since 56 years ago, wearable RFID readers on a hand have appeared on the fields of health care and inspection services, so that they can use their both hands at their working places freely without holding their reader. For achieving such situation, a low-profile CP reader antenna is required for wearable devices with a compact design, and directing its main beam parallel to the ground plane can make the maximum use of the advantages of the low-profile design [10].

Recently, low-profile and small CP antennas have still received a lot of research attention, although other types of UHF RFID reader antennas with meandered, microstrip, and helical element have been published in the literature [4-9]. In [4], an antenna with four meandered monopole elements fed by a series feeding network has been reported, and another antenna with arrayed two bent elements is presented in [5]. In [6], double-sided, crossed-dipole antenna for CP radiation loaded with two metal strips for phase delay is published. A compact circularly polarized microstrip antenna has been presented in [7]. Furthermore, some microstrip antennas for typical commercial handheld readers are linearly or circularly polarized. However, such antennas based on microstrip antennas limit the size and the bandwidth, and the main beam of those is directed to the normal direction to the ground [8]. Some study groups have reported horizontally polarized printed loop antennas in $[11,12]$, and some groups 


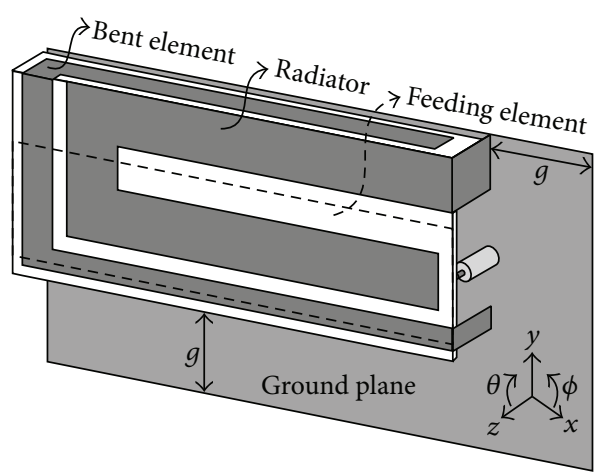

(a)

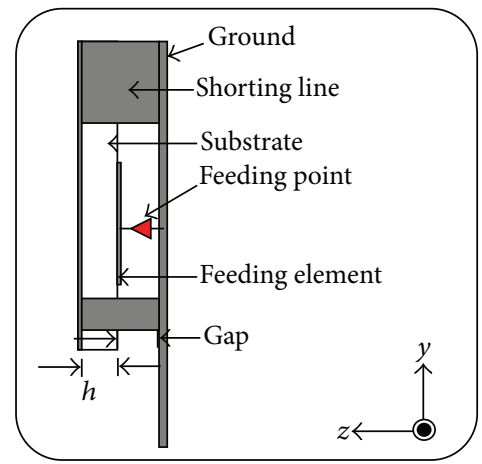

(b)

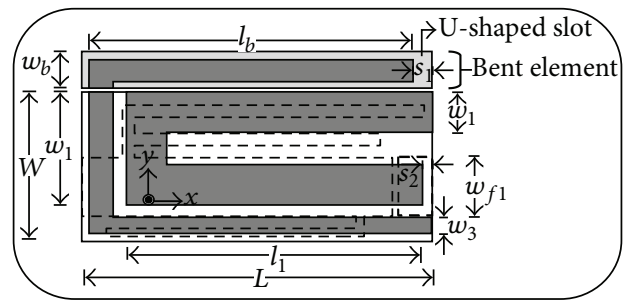

(c)

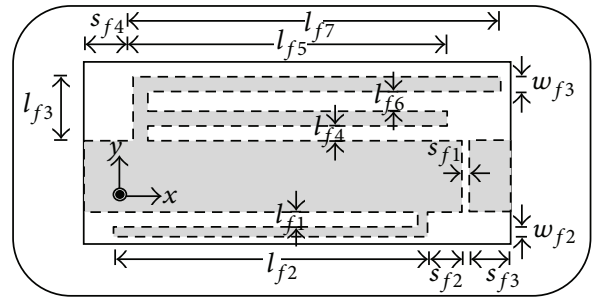

(d)

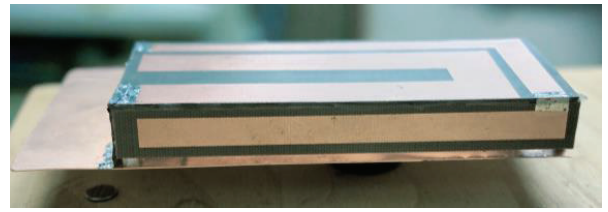

(e)

Figure 1: Geometry of the proposed antenna. (a) Perspective view, (b) side view, (c) radiating element, (d) feeding element, and (e) photograph of the fabricated antenna.

have studied on open-loop antennas generating CP $[13,14]$. Moreover, an inverted-L CP antenna and a slender CP antenna have been reported in $[15,16]$, respectively. However, the main beam direction is not parallel to the ground, and the bandwidth is not sufficient. A study group involving one of the authors has recently reported a low-profile antenna with high radiation efficiency in $[17,18]$, but the polarization is linear. For now, as far as the authors know, almost no one has reported on circularly polarized and low-profile antennas radiating parallel to the ground plane.

In this paper, a compact and low-profile antenna for radiating CP parallel to the ground plane is proposed for RFID readers at UHF band (from $920 \mathrm{MHz}$ to $925 \mathrm{MHz}$ ). In Section 2, the antenna design and characteristics of the proposed antennas are discussed. The principle to generate $\mathrm{CP}$ in this antenna is also discussed in Section 3. In Section 4, the design process is presented. Finally, the discussions in this paper are concluded in Section 5.

\section{Antenna Design}

In this section, the antenna design is presented. The antenna is designed using the CST MW Studio [19]. Figure 1 shows the proposed antenna structure consisting of double U-shaped strips and a capacitive feeding structure of both sides of Arlon Diclad522 $\left(\varepsilon_{r}=2.6\right)$ with a thickness of $h=0.8 \mathrm{~mm}$. The dimension is $L=87 \mathrm{~mm}\left(0.27 \lambda_{0}\right) \times W=37 \mathrm{~mm}\left(0.11 \lambda_{0}\right)$ in length and width. The air gap between radiating element and ground plane is chosen as $11.8 \mathrm{~mm}\left(0.036 \lambda_{0}\right)$ as shown in Figure 1(b). The length and width of double U-shape are optimized because these dimensions affect the resonance frequency at which the length of $U$-shape is $\lambda_{0} / 4$ as shown in
Figure 1(c). One of the arms of the U-shape (bent element) is bent by $90^{\circ}$ in the $x-y$ plane from the radiating element. This forms a U-shaped slot with the ground plane on the bent element in the $z$-x plane. Figure 1(d) shows the capacitive feeding structure which is installed underneath the radiator (double U-shaped elements) and includes an L-shaped stub and an F-shaped stub with a capacitive gap for matching. A photograph of the fabricated antenna is shown in Figure 1(e). The ground plane size is chosen so as to minimize the axial ratio (AR) in the $y$-direction and not to allow the leakage current on the coaxial cable. The ground plane size is extended in the $+x$ - and $-y$-directions with the same size by $g=20 \mathrm{~mm}$, respectively from the substrate dimension. This effect will be discussed in Section 4 .

The double U-shaped radiator determines the resonant frequency. Considering the principle to generate $\mathrm{CP}$ discussed later, the structure should have a half-cut structure of the split-ring resonator antenna [20] with the same resonant frequency as shown in Figure 2. For making a low-profile structure on the ground plane, the feeding structure shown in Figure 1(d) should be used so as to keep sufficient impedance characteristics as discussed later. Furthermore, a part of the arms should be bent by $90^{\circ}$ in the $x-y$ plane, so that the main beam can be directed in the $y$-direction. Table 1 shows the optimized structural parameters of the proposed antenna.

Figure 3 shows simulated and measured $\left|S_{11}\right|$ characteristics. The simulated and measured $\left|S_{11}\right|$ bandwidth at $-10 \mathrm{~dB}$ are found from $916 \mathrm{MHz}$ to $934 \mathrm{MHz}(1.8 \%)$ and $916 \mathrm{MHz}$ to $930 \mathrm{MHz}(1.4 \%)$, respectively, covering a typical UHF RFID band (920 to $925 \mathrm{MHz}$; Thailand). The simulated and measured radiation patterns of left-hand CP (LHCP) and righthand CP (RHCP) at $925 \mathrm{MHz}$ are shown in Figure 4 in $x-y$ 
TABLE 1: The optimized structural parameters.

\begin{tabular}{lccccccc}
\hline Parameter & Size in $\mathrm{mm}$ & Parameter & Size in $\mathrm{mm}$ & Parameter & Size in mm & Parameter & Size in mm \\
\hline$W$ & 87.0 & $w_{b}$ & 9.0 & $s_{f 1}$ & 1.5 & $l_{f 4}$ & 3.0 \\
$L$ & 37.0 & $l_{b}$ & 80.5 & $s_{f 2}$ & 7.0 & $l_{f 5}$ & 61.0 \\
$h$ & 0.8 & $s_{1}$ & 10.0 & $s_{f 3}$ & 8.5 & $l_{f 6}$ & 4.0 \\
$w_{1}$ & 28.0 & $s_{2}$ & 5.0 & $s_{f 4}$ & 10.0 & $l_{f 7}$ & 75.0 \\
$w_{2}$ & 10.0 & $w_{f 1}$ & 14.5 & $l_{f 1}$ & 3.0 & 9 & 20.0 \\
$w_{3}$ & 4.0 & $w_{f 2}$ & 2.0 & $l_{f 2}$ & 64.0 & Gap & 11.8 \\
$l_{1}$ & 73.5 & $w_{f 3}$ & 3.0 & $l_{f 3}$ & 13.0 & & \\
\hline
\end{tabular}

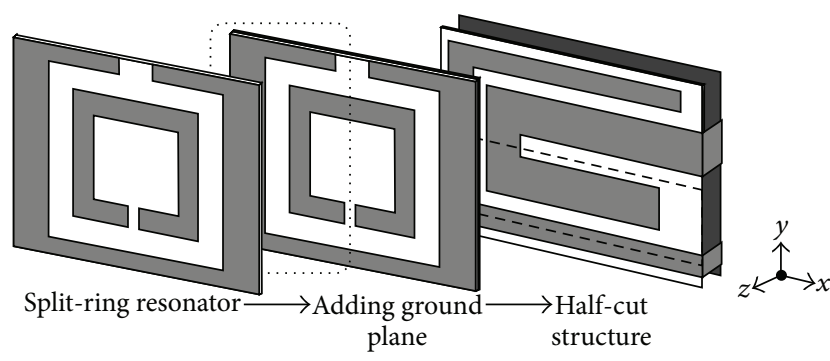

FIgURE 2: The antenna evolution.

plane and $y-z$ plane. The simulated and measured half-power beamwidth (HPBW) of RHCP are $105^{\circ}$ and $110^{\circ}$, respectively, in $y-z$ plane where the main beam (RHCP) direction is declined only by $20^{\circ}$ from the $y$-direction (parallel to the ground plane). However, the obtained gain in the $y$-direction is slightly lower by only $0.6 \mathrm{~dB}$ than that in the main beam direction. The simulated and measured gains are $1.8 \mathrm{dBic}$ and $2.8 \mathrm{dBic}$, respectively, in $y$-direction. The radiation patterns of RHCP and LHCP have been normalized by the simulated and measured peak gain of RHCP (copolarization), respectively. Therefore, we can understand that, in the $y$-direction, the cross-polarization of LHCP is more than $15 \mathrm{~dB}$ lower than RHCP. This indicates that the AR in the $y$-direction is less than $3 \mathrm{~dB}$. Furthermore, considering the discussion below, it can be said that the measured results in the radiation patterns show reasonable agreements with the simulated results. As shown in Figure 5(a), the AR in $y-z$ plane is less than $3 \mathrm{~dB}$ in the $\theta$ angle range from $70^{\circ}$ to $95^{\circ}$ and $70^{\circ}$ to $90^{\circ}$ for simulated and measured results, respectively. In the boresight direction at $\theta=90^{\circ}$, the measured AR is higher by approximately $1 \mathrm{~dB}$ than the simulated $\mathrm{AR}$, although the measured $\mathrm{AR}$ is at around $3 \mathrm{~dB}$. Considering the results of radiation performances discussed above with Figures 4 and 5 , we can find small differences between the simulated and measured results, although they show reasonable agreements. The small differences are mainly due to fabrication errors, especially those are related to our hand-made fabrications of U-shaped slot. As shown in Figure 5(b), the $3 \mathrm{~dB}$ AR in the $y$ direction can also be observed in the UHF band. As a result, we can understand that the proposed antenna can radiate CP in the $y$-direction covering the UHF RFID band.

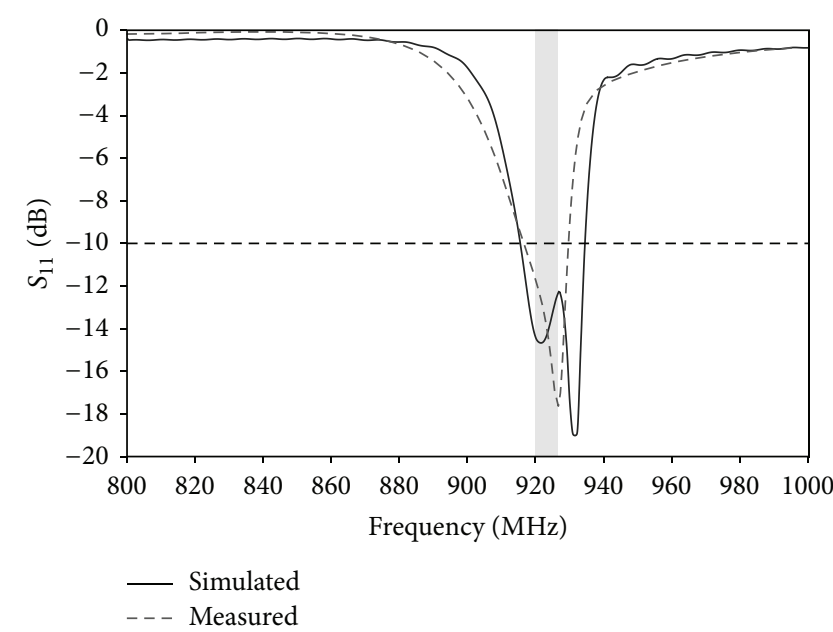

FIgURE 3: Simulated and measured $\left|S_{11}\right|$.

\section{Principle of Generating Circular Polarization}

The generation mechanism of $\mathrm{CP}$ is discussed in this section. The antenna elements have two metallic layers sandwiching the dielectric substrate to equip the radiator and the feeding structure with the L-shaped and F-shaped stubs. The radiator and the feeding structure have been overlapped as shown in Figure 1(c). The e-field (electric field) distributions at different phases are shown in Figure 6. At phase $=0^{\circ}$, the strongest field of Z-component is found mainly around the U-shaped slot on the bent element as shown in Figure 6(a). As shown in Figure 6(b), e-field directed to $+z$ with high density can be found; however, the e-field to $-z$ shows low density. This asymmetrical distribution is due to the difference in the presence of the radiator and ground plane. At phase $=90^{\circ}$, strong field directed in $x$ - and $\pm z$ - directions can be found on the U-shaped slot as shown in Figure 6(c); however, the components in $\pm z$ directions finally are canceled out by each other in the far field. Since the length between the feeding point (around $x=0 \mathrm{~mm}$ ) on the feeding line and the bent part of the U-shaped slot is about half wavelength, the voltage at the feeding line gets lower at $90^{\circ}$ phase than that at the bent point in the U-shaped slot. Therefore e-field is pulled into the feeding line as shown in Figure 6(d) resulting in having a symmetrical distribution between $\pm z$-directions. As 

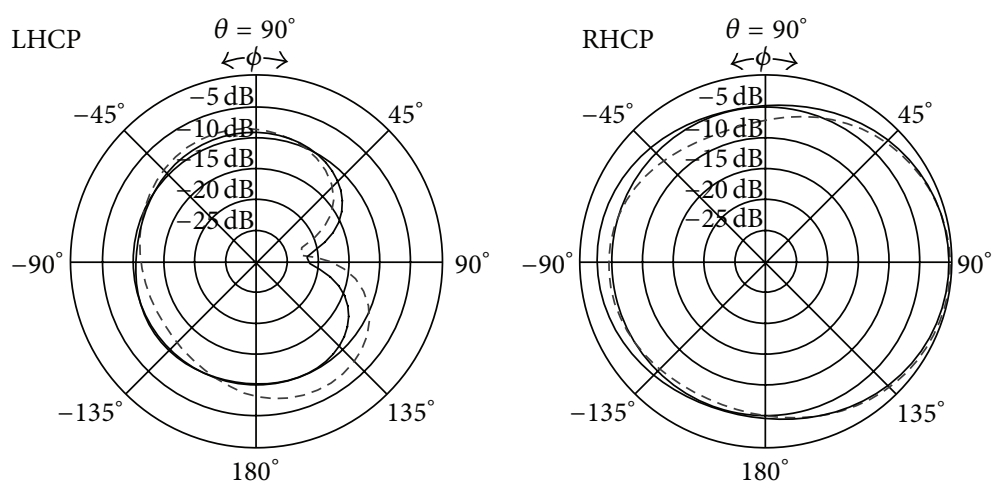

(a)
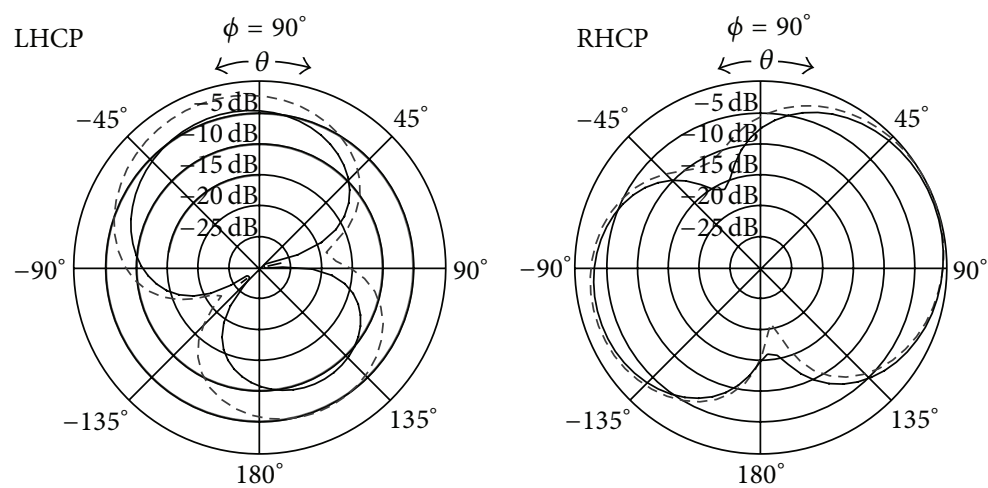

- Simulated

(b)

Figure 4: Radiation patterns at $925 \mathrm{MHz}$. (a) $x-y$ plane and (b) $y-z$ plane.

a result, at phase $=90^{\circ}$, only the X-component at the bent part of the U-shaped slot contributes to radiate. With the same analogy, the e-field generates CP with $90^{\circ}$-phase difference of orthogonal e-field components at phase $=180^{\circ}$ and $270^{\circ}$, respectively.

On the other hand, this antenna radiates the same sense of $\mathrm{CP}$, although the $3 \mathrm{~dB} \mathrm{AR}$ can be obtained at $\theta=-120^{\circ}$. This radiation is explained by the e-field behavior around the feeding point outside of the radiating element. At phase $=$ $0^{\circ}$, the normal e-field can be observed by the same principle of the U-shaped slot mentioned above. At phase $=90^{\circ}$, the e-field is pulled into the feeding point following the same principle of the above explanation. Therefore, the e-field rotates in the clockwise direction with respect to the $-y$ direction.

\section{Effects of Structural Parameters}

The proposed antenna is a low profile and can radiate CP in the $y$-direction with respect to the ground plane. This section discussed the effects of structural parameters on the AR and antenna gain.
4.1. Effects of the Bent Element. One of interests in this antenna is a fact that CP is radiated in the $y$-direction with $\theta=90^{\circ}$, even though the structure is low profile. Bending a part of U-shaped elements with a bent angle $\alpha$ (from $0^{\circ}$ to $90^{\circ}$ ), as shown in Figure 7, contributes to increase the $\theta$ angle of main beam direction in the $y-z$ plane $\left(\phi=90^{\circ}\right)$. The input impedance characteristics can be kept the same, as shown in Figure 8(a), in this range of $\alpha$. When $\alpha=0^{\circ}$, the peak gain can be observed in the $z$ direction at $0^{\circ}$ as shown in Figure 8(b). With an increase in $\alpha$ from $30^{\circ}$ to $90^{\circ}$, the main beam direction $\theta$ is shifted from $0^{\circ}$ to $70^{\circ}$ in the $y-z$ plane. For $\alpha=90^{\circ}$, the $3 \mathrm{~dB}$ AR can be observed at $\theta=90^{\circ}$ in the $y$ - $z$ plane as shown in Figure 8(c).

\subsection{Effects of L-Shaped and the Capacitive Gap Feeding} Structure. Effects of the stubs in the feeding structure are discussed. The use of a coupled feeding line with the radiator element is one of the techniques for designing low-profile antennas [17] to cancel the inductivity at a frequency range with around $50 \Omega$ impedance. Figure 9 shows the evolution of feeding structure that starts from a simple rectangular strip to the proposed structure with adding the capacitive gap, the L-shaped stub on a lower edge of the line, the short stub, the long stub, and the F-shaped stub on an upper edge. 


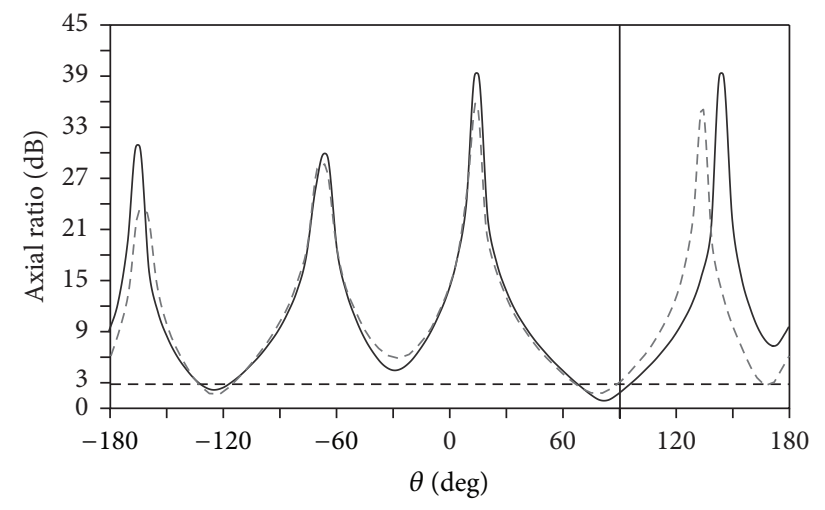

- Simulated

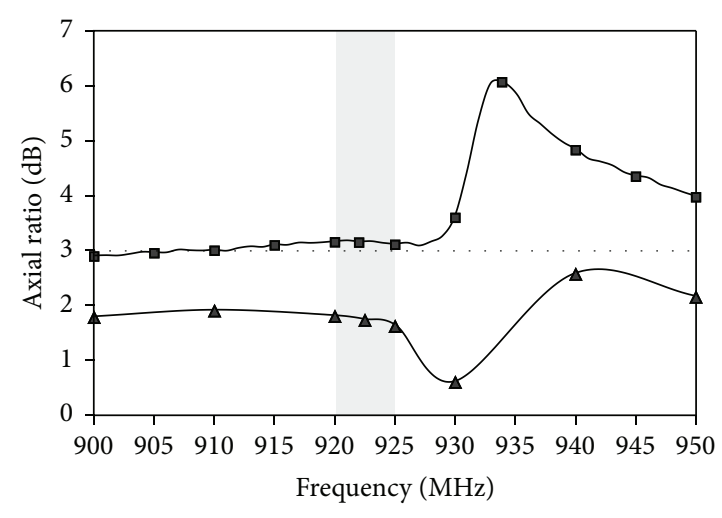

$\triangle$ Simulated

(a)

(b)

Figure 5: Simulated and measured AR pattern of the proposed antenna in $y$ - $z$ plane $\left(\phi=90^{\circ}\right)$ at $925 \mathrm{MHz}$ (a) as a function of $\theta$ and (b) as a function of the frequency at $\theta=90^{\circ}$.

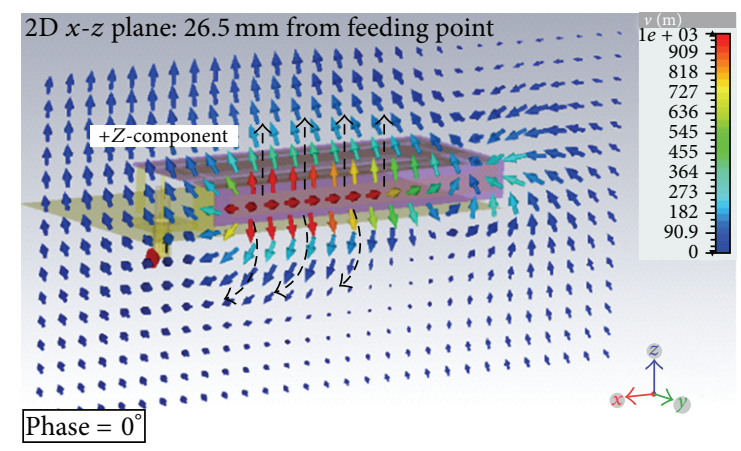

(a)

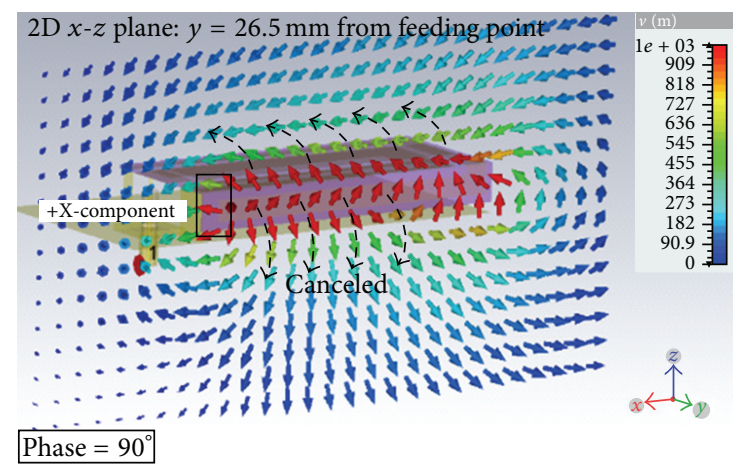

(c)

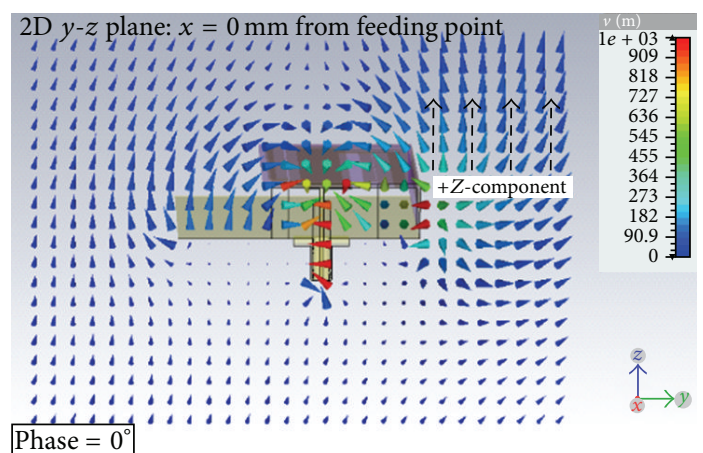

(b)

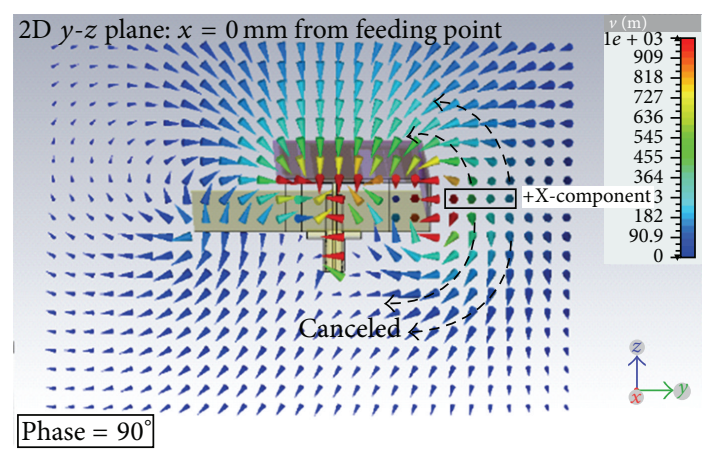

(d)

FiguRE 6: Electric field distributions in different phases at $920 \mathrm{MHz}(\mathrm{a})$ in the $x-z$ plane at phase $=0^{\circ},(\mathrm{b})$ in the $y-z$ plane at phase $=0^{\circ}$, (c) in the $x-z$ plane at phase $=90^{\circ}$, and (d) in the $y$ - $z$ plane at phase $=90^{\circ}$.

For matching to $50 \Omega$ with a sufficient bandwidth, the capacitive gap and the L-shaped stub are installed resulting in the shift of the characteristics as shown in Figure 10. With the simple rectangular feeding structure, the input impedance characteristic shows a small kink (with a dotted line) at the right side of the Smith chart centering the horizontal axis. When only the capacitive gap is installed, the kink is shifted to a different place (the kink shown with a dashed line) along the circle of a real axis counterclockwisely. After this, when the L-shaped stub having a parallel capacitance is installed, the kink, shown with a solid line, is magnified passing the center showing a narrow bandwidth since the kink size is still bigger than the circle of VSWR = 2. 


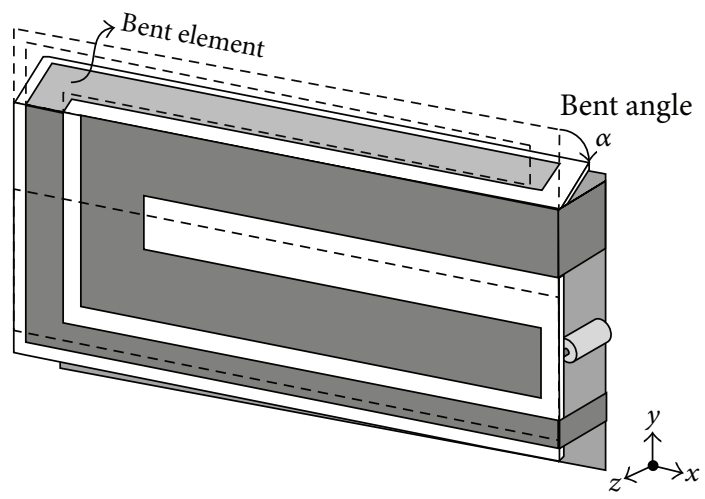

FIGURE 7: Direction of bending angle $\alpha$ on the element.

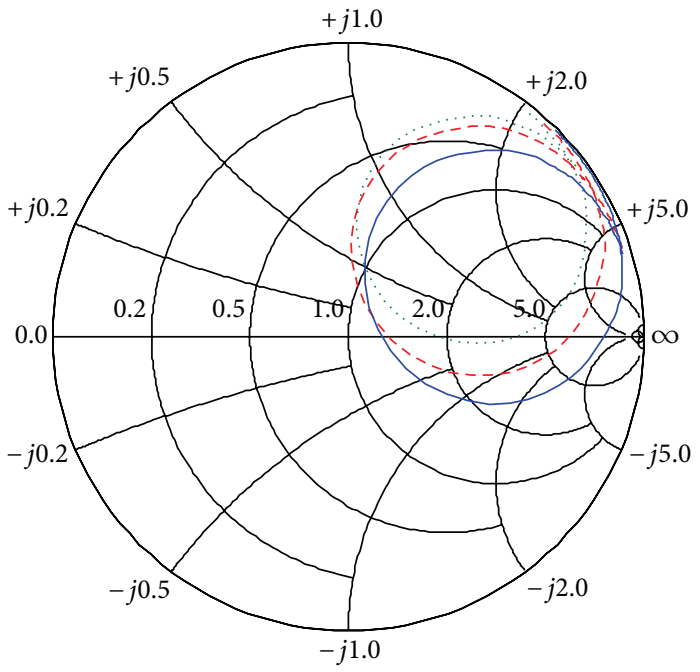

$\begin{aligned} \cdots \alpha & =0^{\circ} \\ --\alpha & =50^{\circ} \\ -\alpha & =90^{\circ}\end{aligned}$
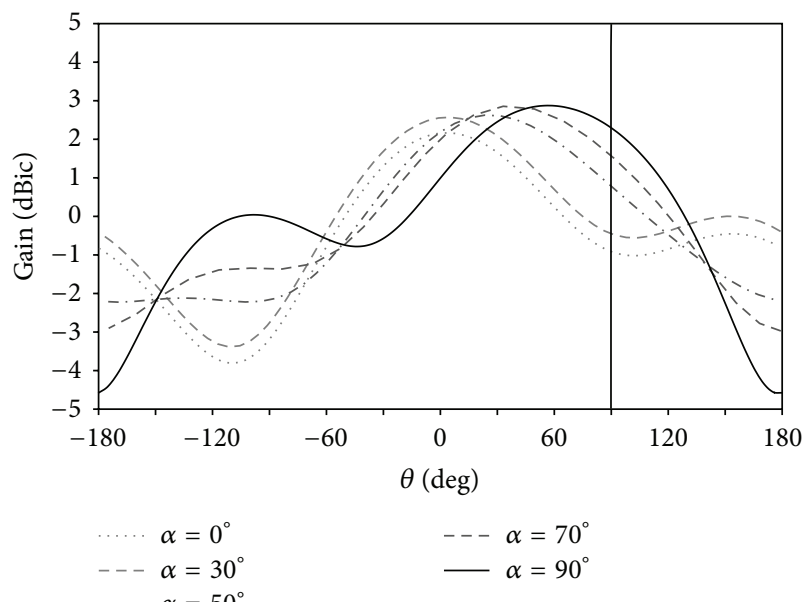

(b)
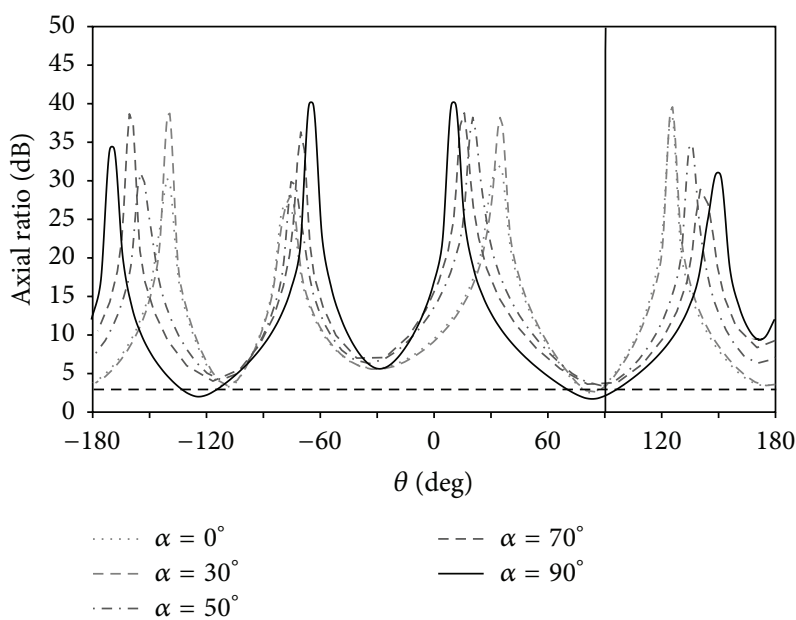

(c)

FIGURE 8: Simulated results of (a) input impedance characteristics with $\alpha$, (b) antenna gain pattern, and (c) AR pattern of the proposed antenna in $y-z$ plane at $925 \mathrm{MHz}$ as a function of the bending angle $\alpha\left(\phi=90^{\circ}\right)$. 


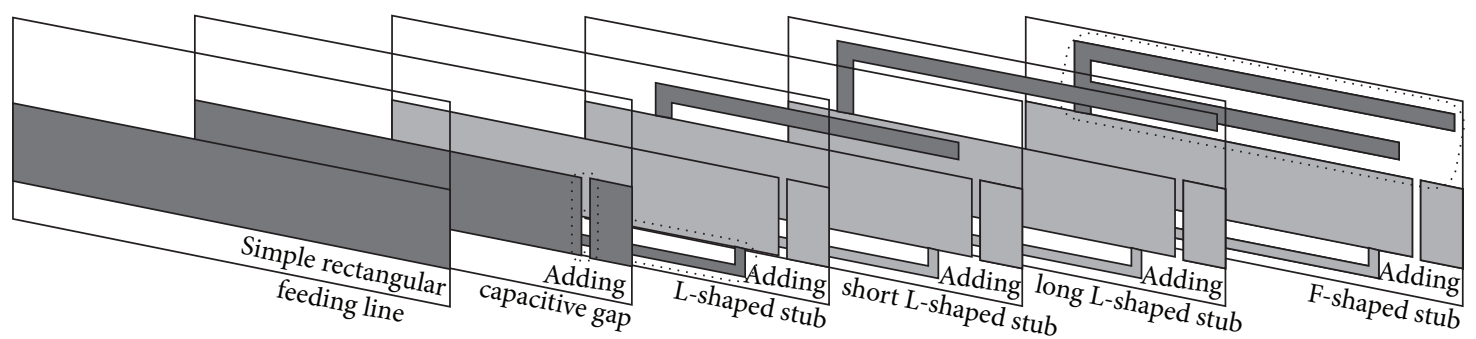

FIGURE 9: Feeding structure evolution.

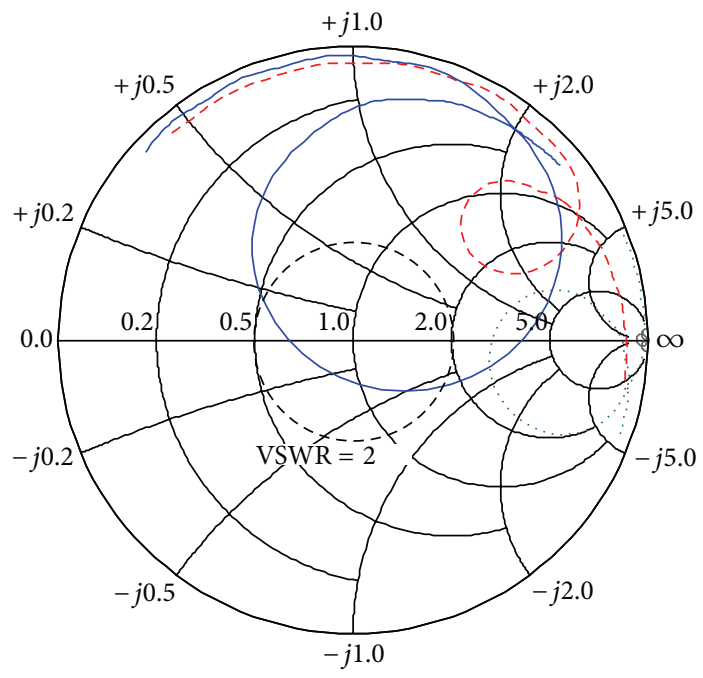

\footnotetext{
... Simple rectangular feeding line

- - - Adding capacitive gap

— Adding capacitive gap

and L-shaped stub
}

FIGURE 10: Simulated input impedance characteristics when the gap and L-shaped stub are installed.

4.3. Effects of F-Shaped Stub Feeding Structure. As the final step, the F-shaped stub is installed for enhancing the bandwidth. The F-shaped stub is a combination of short and long L-shaped stubs. Figure 11(a) shows the effect of installing the short and long L-shaped stubs on input impedance characteristics. When the short stub is installed, the impedance can be matched well to $50 \Omega$ with a sufficient bandwidth; however, as shown in Figure 11(b), the main beam direction is around $60^{\circ}$. On the other hand, when the long stub is installed, the main beam direction is shifted closer to $\theta=90^{\circ}$ as shown in Figure 11(b); however, the impedance bandwidth is narrow as shown in Figure 11(a) with a larger kink.

The F-shaped stub has the both functions of the short and long stubs; that is, the short stub is required for matching, and the long stub is for radiating $\mathrm{CP}$ in the direction at $\theta=$ $90^{\circ}$. Similarly, the F-shaped stub makes a small kink inside the circle of VSWR $=2$ in the Smith chart and also makes the main beam direction closer to $\theta=90^{\circ}$ resulting in $3 \mathrm{~dB} A R$ in $+y$-direction as shown in Figures 11(b) and 11(c). With the metallic arm along the $+y$-direction of the long or F-shaped stub, the e-field inside the radiator can be perpendicular to the ground plane and the stub element nearby the U-shaped slot. This behavior leads to direct the main beam closer to $\theta$ $=90^{\circ}$. As a result, in the final structure, the simulated and measured impedance can be matched to $50 \Omega$ as shown in Figure 11(a) with the simulated bandwidth of $18 \mathrm{MHz}$, and the main beam direction is at $\theta=70^{\circ}$ as shown in Figure 4. In the direction at $\theta=90^{\circ}, \mathrm{AR}$ can be kept less than $3 \mathrm{~dB}$ with a sufficient simulated gain of $1.8 \mathrm{dBic}$.

4.4. Effects of Ground Plane Size. Figure 12(a) shows the variation in AR pattern with the ground plane size. Comparing the size (default) which is the same as the radiator in $x-y$ plane, the ground plane is extended by $g=20 \mathrm{~mm}$ in $+x$ - and $-x$-, $+x$ - and $-y$-, $-x$ - and $-y$-, and $\pm x$ - and $y$-directions at the same time. When the ground is extended in $+x$ and $-y$-directions, the $\mathrm{AR}$ is minimized at around $\theta=90^{\circ}$. This extension in the $+x$ direction contributes to have the e-field, near the open end of radiator, directed in $x$ - or $z$ direction in wider area of $x-z$ plane at phase $=0^{\circ}$ or $90^{\circ}$, respectively. In this case, the HPBW is about $105^{\circ}$ covering the $\theta=90^{\circ}$ direction as shown in Figure 12(b). 


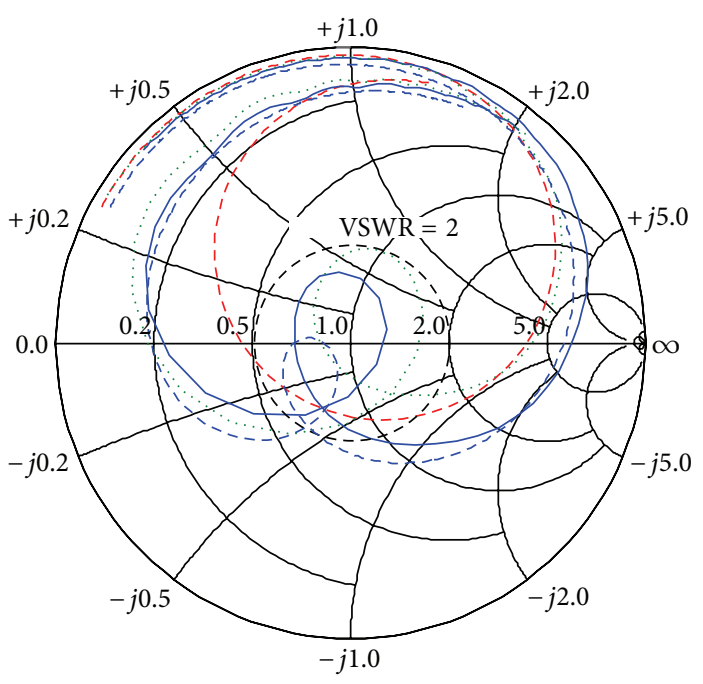

$$
\begin{array}{ll}
\text { _-.- F-shaped } & \text { F-shaped (measured) }
\end{array}
$$

(a)
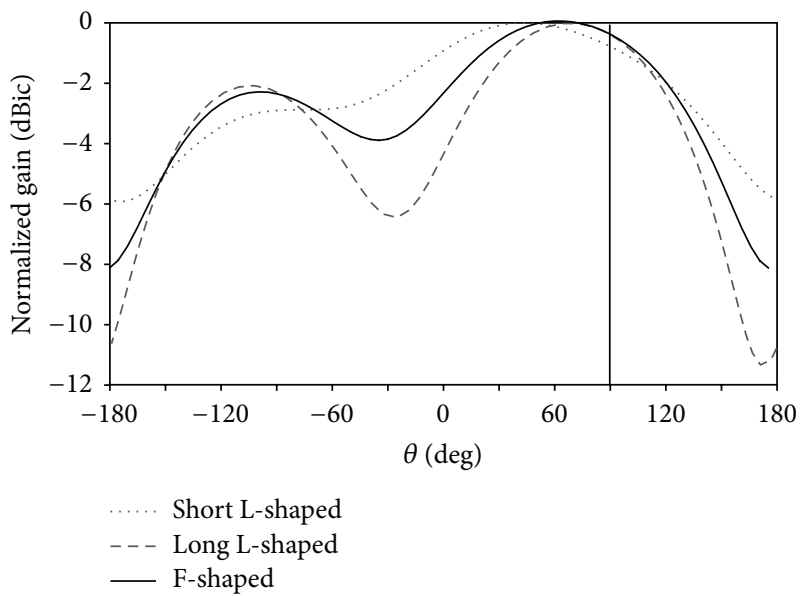

(b)

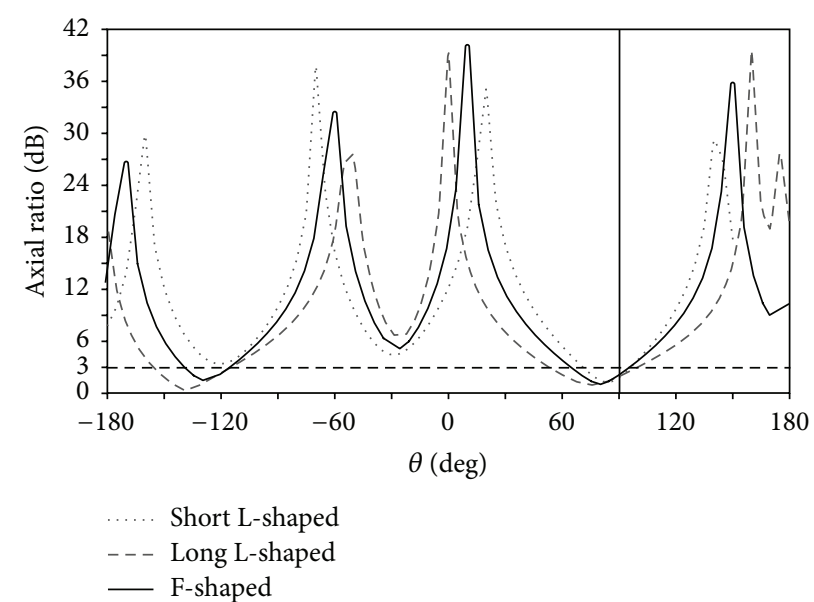

(c)

FIGURE 11: Simulated results of (a) input impedance characteristics, (b) antenna gain, and (c) AR pattern with $\theta \cdot \phi=90^{\circ}$ in $y$ - $z$ plane at $925 \mathrm{MHz}$ when the short, long, and F-shaped stubs are installed.

For the extension in the $+x$ and $-y$-directions, the main beam direction in which the minimum AR can be obtained gets closer to $\theta=90^{\circ}$ with an increase in $g$ from 5 to $25 \mathrm{~mm}$ as shown in Figure 13(a). For $g=25 \mathrm{~mm}$, the angle for the minimum AR is the closest to $\theta=90^{\circ}$; however, the antenna gain at $\theta=90^{\circ}$ is smaller than that for $g=20 \mathrm{~mm}$ as shown in Figure 13(b). Therefore, the parameter $g$ should be chosen as $20 \mathrm{~mm}$ for this design. Choosing $g=20 \mathrm{~mm}$ with the extension in the $+x$ and $-y$-directions, we have confirmed that the ground plane size has a sufficient area enough to suppress the leakage current on the coaxial cable.

\section{Conclusion}

This paper has proposed a low-profile and circularly polarized antenna with double U-shaped arms considering an application for handheld RFID readers at $920 \mathrm{MHz}$ to $925 \mathrm{MHz}$ band. The structure consists of a modified double $\mathrm{U}$-shaped radiator and ground plane. A part of the arms of the radiator has been bent by $90^{\circ}$ in the $x-y$ plane for directing $\mathrm{CP}$ radiation parallel to the ground plane $\left(\theta=90^{\circ}\right)$. For keeping the sufficient impedance bandwidth for the RFID band, some matching stubs and a capacitive gap have been installed on the feeding structure, and the design process has been discussed. In addition to them, effects of the ground plane size on the $\mathrm{CP}$ direction have been discussed, and a sufficient antenna gain has been also confirmed in this direction. The measured results show good agreements with the simulated results. Furthermore, the principle for generating $\mathrm{CP}$ has been analyzed taking notice of the e-field distributions. Based on this principle, the $\mathrm{U}$-shaped slot can contribute to achieve a low-profile antenna for radiating CP parallel to the ground. 


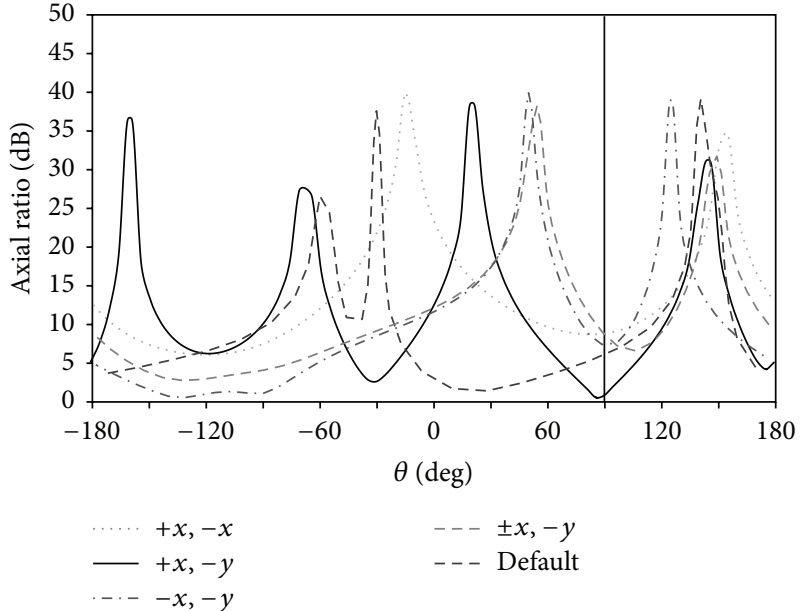

(a)

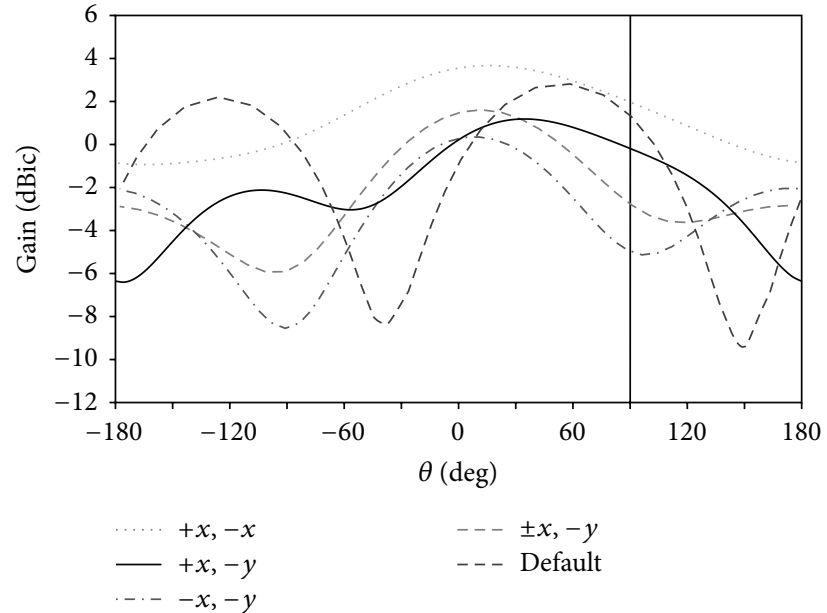

(b)

FIGURE 12: Simulated results of (a) AR pattern and (b) antenna gain in $y$ - $z$ plane at $925 \mathrm{MHz}$ as a function of the ground plane size by $g=$ $20 \mathrm{~mm}\left(\phi=90^{\circ}\right)$

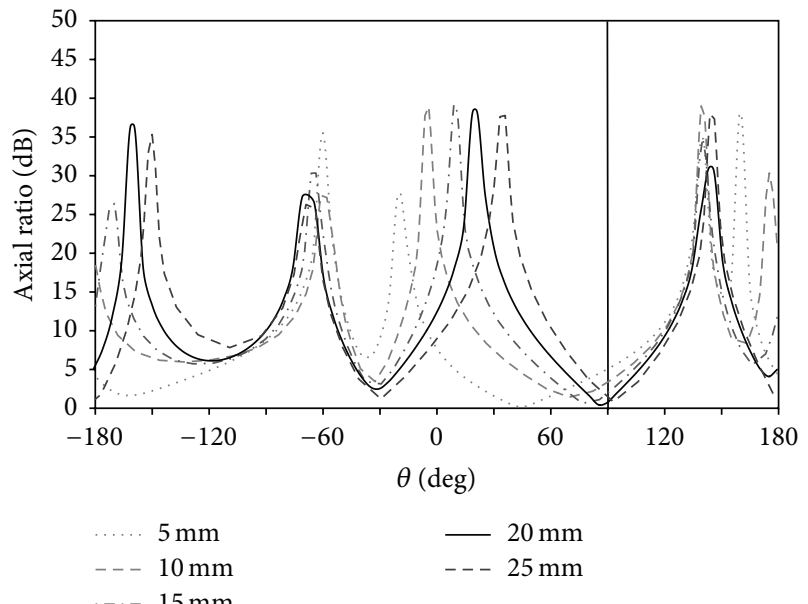

(a)

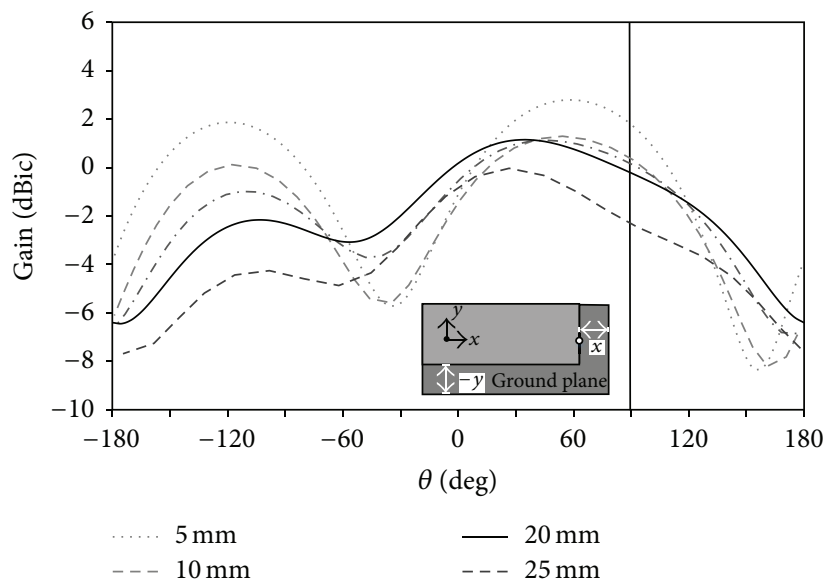

(b)

FIGURE 13: Simulated results of (a) AR pattern and (b) antenna gain in $y-z$ plane at $925 \mathrm{MHz}$ as a function of the extension in $+x$ - and $-y$ direction $g\left(\phi=90^{\circ}\right)$.

\section{Acknowledgment}

This work is supported by the Thailand Research Fund (TRF) through the Royal Golden Jubilee Ph.D. Program under Grant no. PHD/0324/2552.

\section{References}

[1] K. Finkenzeller, RFID Handbook, Wiley, New York, NY, USA, 2nd edition, 2004.

[2] X. Chen, G. Fu, S.-X. Gong, Y.-L. Yan, and W. Zhao, "Circularly polarized stacked annular-ring microstrip antenna with integrated feeding network for UHF RFID readers," IEEE Antennas and Wireless Propagation Letters, vol. 9, pp. 542-545, 2010.

[3] W.-G. Lim, W.-I. Son, K.-S. Oh, W.-K. Kim, and J.-W. Yu, "Compact integrated antenna with circulator for UHF RFID system," IEEE Antennas and Wireless Propagation Letters, vol. 7, pp. 673-675, 2008.

[4] J.-H. Bang, C. B. Ochir, H.-S. Koh, E.-J. Cha, and B.-C. Ahn, "A small and lightweight antenna for handheld RFID reader applications," IEEE Antennas and Wireless Propagation Letters, vol. 11, pp. 1076-1079, 2012.

[5] J. J. Yu and S. Lim, "Design of an electrically small, circularly polarized, parasitic array antenna for an active $433.92 \mathrm{MHz}$ RFID handheld reader," IEEE Transactions on Antennas and Propagation, vol. 60, no. 5, pp. 2549-2554, 2012.

[6] Y.-F. Lin, Y.-K. Wang, H.-M. Chen, and Z.-Z. Yang, "Circularly polarized crossed dipole antenna with phase delay lines for RFID handheld reader," IEEE Transactions on Antennas and Propagation, vol. 60, no. 3, pp. 1221-1227, 2012.

[7] N. Nasimuddin, Z. N. Chen, and X. Qing, "Asymmetric-circular shaped slotted microstrip antennas for circular polarization 
and RFID applications," IEEE Transactions on Antennas and Propagation, vol. 58, no. 12, pp. 3821-3828, 2010.

[8] P. V. Nikitin and K. V. S. Rao, "Helical antenna for handheld UHF RFID reader," in Proceedings of the 4th Annual IEEE International Conference on RFID (RFID '10), pp. 166-173, Orlando, Fla, USA, April 2010.

[9] W.-I. Son, M.-Q. Lee, and J.-W. Yu, "Module integrated antenna with circular polarization for mobile UHF RFID reader," IEEE Transactions on Microwave Theory and Techniques, vol. 59, no. 4, pp. 1157-1165, 2011.

[10] S.-H. Chang and W.-J. Liao, "A novel dual band circularly polarized GNSS antenna for handheld devices," IEEE Transactions on Antennas and Propagation, vol. 61, no. 2, pp. 555-562, 2013.

[11] K. Wei, Z. Zhang, and Z. Feng, "Design of a wideband horizontally polarized omnidirectional printed loop antenna," IEEE Antennas and Wireless Propagation Letters, vol. 11, pp. 4952, 2012.

[12] C. C. Lin, L. C. Kuo, and H. R. Chuang, "A horizontally polarized omnidirectional printed antenna for WLAN applications," IEEE Transactions on Antennas and Propagation, vol. 54, no. 11, pp. 3551-3556, 2006.

[13] R.-L. Li, V. F. Fusco, and H. Nakano, "Circularly polarized openloop antenna," IEEE Transactions on Antennas and Propagation, vol. 51, no. 9, pp. 2475-2477, 2003.

[14] R. Li, G. DeJean, J. Laskar, and M. M. Tentzeris, "Investigation of circularly polarized loop antennas with a parasitic element for bandwidth enhancement," IEEE Transactions on Antennas and Propagation, vol. 53, no. 12, pp. 3930-3939, 2005.

[15] X. Yang, Y. Z. Yin, W. Hu, and S. L. Zuo, "Low-profile, small circularly polarized inverted-L antenna with double-folded arms," IEEE Antennas and Wireless Propagation Letters, vol. 9, pp. 767-770, 2010.

[16] Y. Zhang and T. Fukusako, "Design of circularly polarized low-profile and slender antenna with a helical element," IEEE Antennas and Wireless Propagation Letters, vol. 11, pp. 523-526, 2012.

[17] Y. Saito and T. Fukusako, "Low-profile and electrically small meander-line antenna using a capacitive feed structure," IEEE Antennas and Wireless Propagation Letters, vol. 11, pp. 1281-1284, 2012.

[18] Y. Tanogashira and T. Fukusako, "Directional radiation pattern of surface wave antenna using dogbone structure," IEICE Communication Express, vol. 1, no. 2, pp. 85-88, 2012.

[19] CST-Microwave Studio and User's Manual CST-Microwave Studio, Framingham, Mass, USA, 2006.

[20] K. Lertsakwimarn, R. Suwalak, and C. Phongcharoenpanich, "A compact loop antenna with parasitic split ring for UHF RFID application," in Progress in Electromagnetics Research Symposium (PIERS '13), pp. 219-222, Taipei, Taiwan, 2013. 

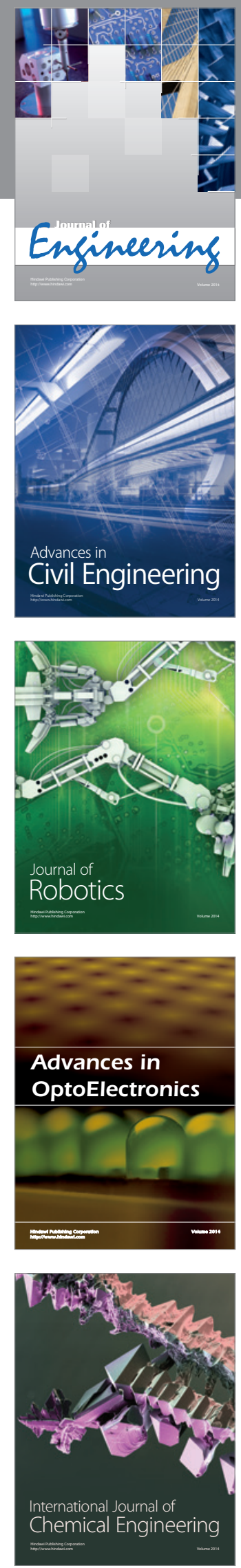

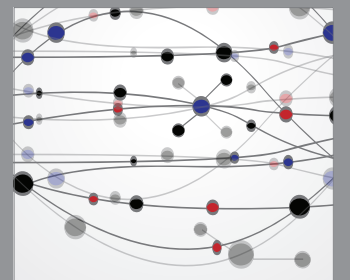

The Scientific World Journal
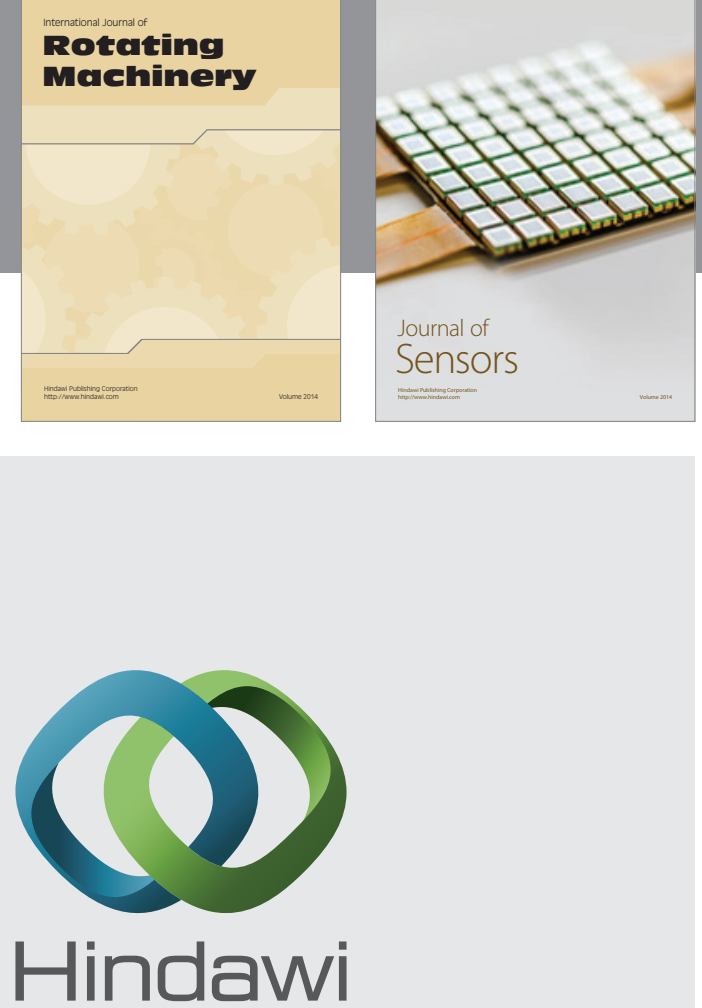

Submit your manuscripts at http://www.hindawi.com
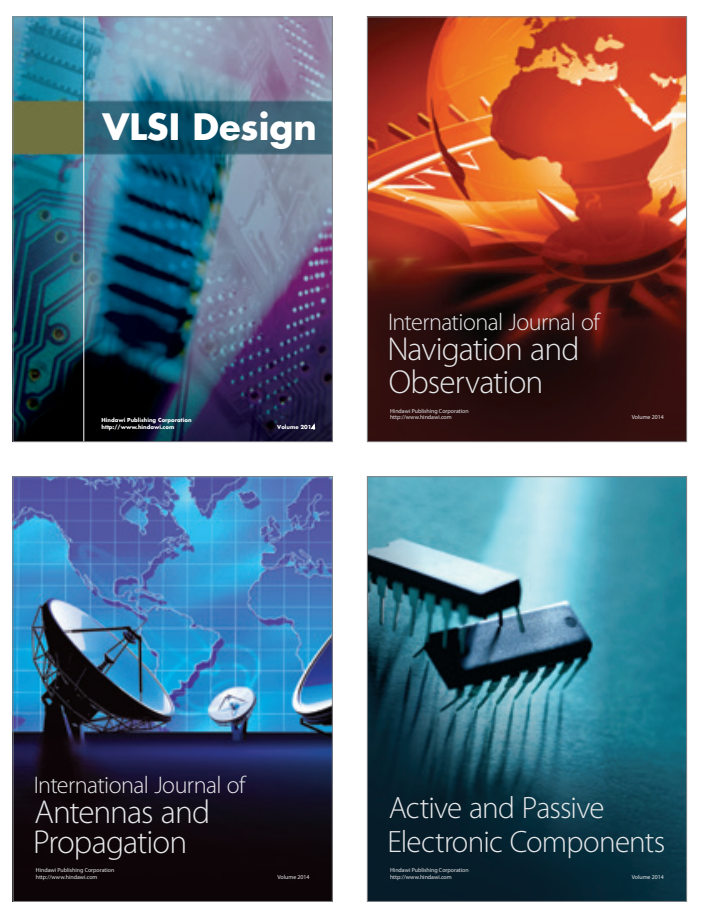
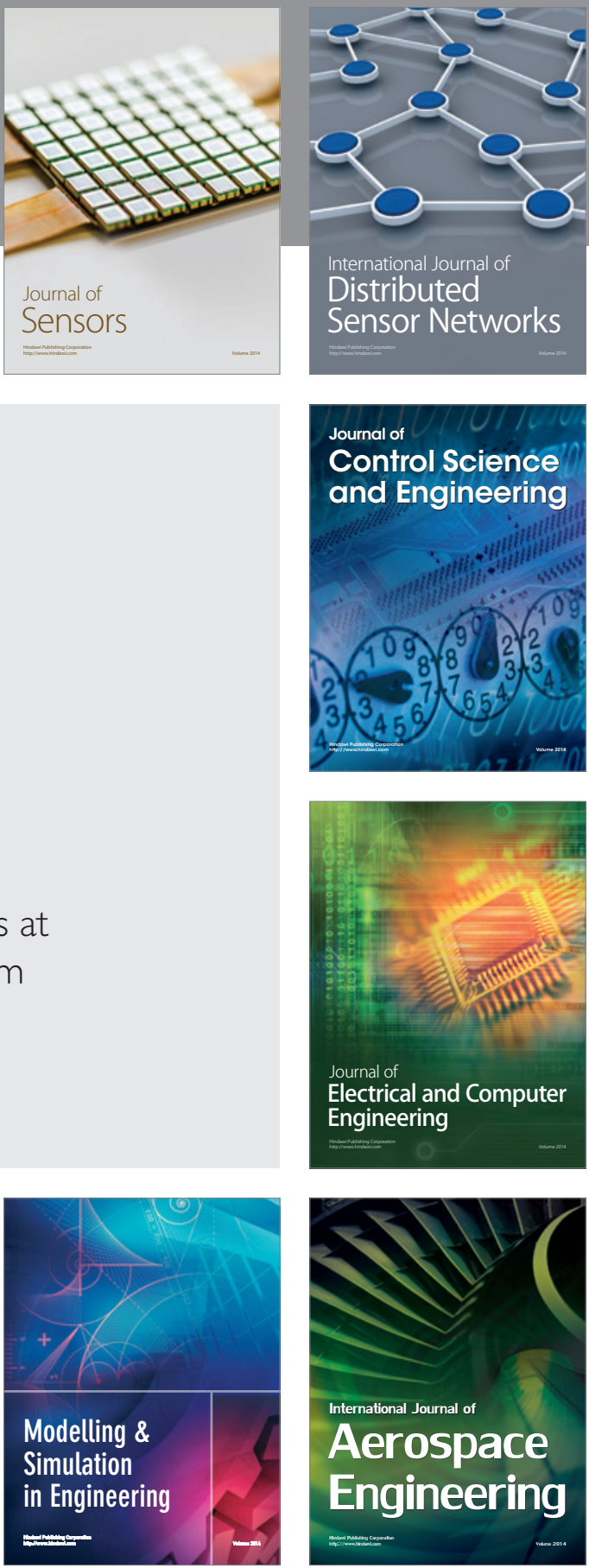

Journal of

Control Science

and Engineering
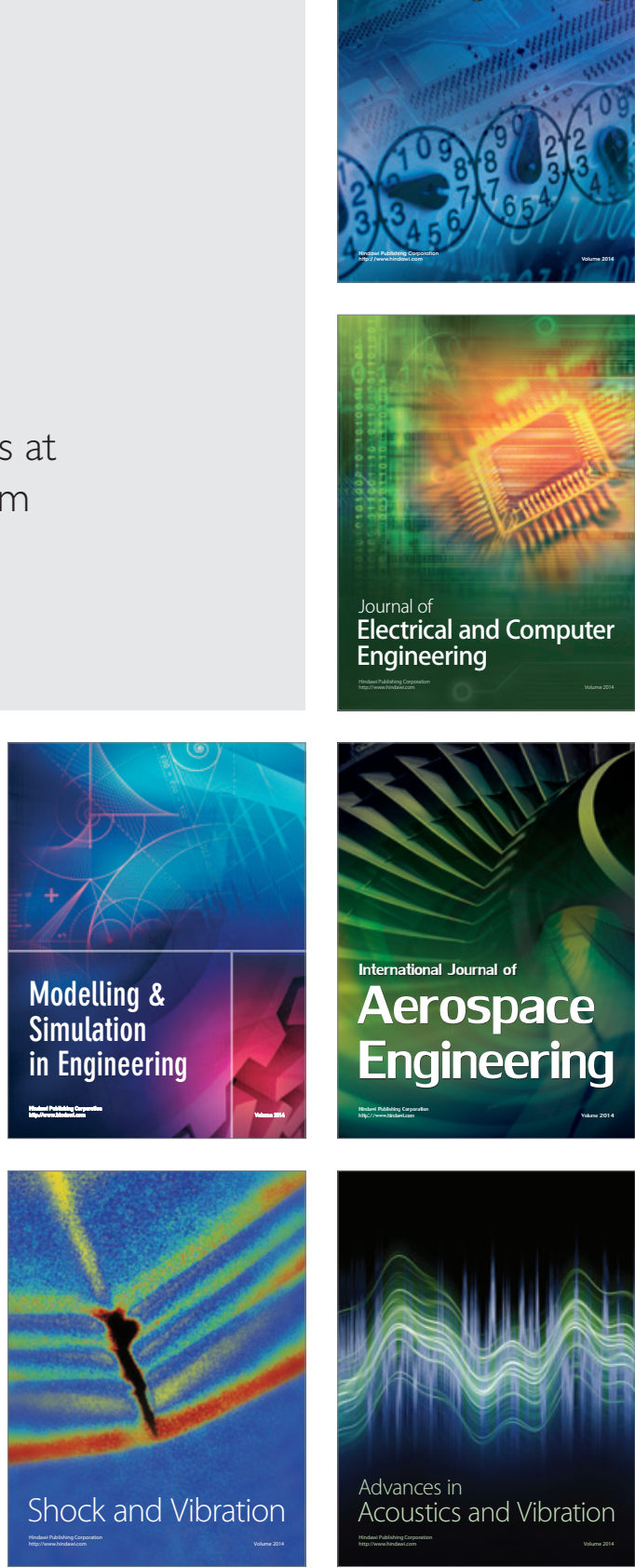